\title{
The photodecomposition mechanism of tert-butyl-9-methylfluorene- 9-percarboxylate: new insight from femtosecond IR spectroscopy
}

\author{
Christian Reichardt, ${ }^{a}$ Jörg Schroeder ${ }^{a b}$ and Dirk Schwarzer* ${ }^{*}$ \\ Received 15th April 2008, Accepted 22nd May 2008 \\ First published as an Advance Article on the web 27th June 2008 \\ DOI: $10.1039 / \mathbf{b 8 0 6 3 5 9 a}$
}

The ultrafast photodissociation of tert-butyl-9-methylfluorene-9-percarboxylate (TBFC) is studied by mid-infrared transient absorption spectroscopy after UV excitation at $266 \mathrm{~nm}$. By means of ${ }^{13} \mathrm{C}$-labeled TBFC and additional DFT calculations transient IR bands in the fingerprint region were unambiguously assigned to the methylfluorenyl radical. The experiments show that the fragmentation is controlled by the $\mathrm{S}_{1}$-lifetime of TBFC and, dependent on the solvent, within 0.8-2.1 ps leads to tert-butyloxy and methylfluorenyl radicals plus $\mathrm{CO}_{2}$ via concerted bond breakage of the $\mathrm{O}-\mathrm{O}$ and the fluorenyl- $\mathrm{C}$ (carbonyl) bond. In accordance, the $\mathrm{CO}_{2}$ quantum yield is determined to be unity.

\section{Introduction}

Technical polymerization processes on a large scale make use of organic peroxides as initiators, which as such have been the subject of numerous studies providing much of the experimental basis of free radical chemistry. ${ }^{1,2}$ Both a stepwise and a concerted mechanism have been suggested for peroxide thermal fragmentation, i.e., initial $\mathrm{O}-\mathrm{O}$-bond cleavage in the peroxy compound $\mathrm{RC}(\mathrm{O}) \mathrm{O}-\mathrm{OR}^{\prime}$ followed by subsequent decarboxylation of the $\mathrm{RCO}_{2}{ }^{\bullet}$ radical, and a concerted two bond cleavage yielding instantaneously $\mathrm{R}^{\bullet}, \mathrm{CO}_{2}$, and ${ }^{\bullet} \mathrm{OR}^{\prime}$. While trapping experiments established the existence of the benzoyloxyl radical $\mathrm{C}_{6} \mathrm{H}_{5} \mathrm{CO}_{2}{ }^{\bullet}$ as an intermediate, ${ }^{3}$ Bartlett and coworkers could show that the thermal decomposition rate in a series of peroxyesters increases with increasing stability of the alkyl radical formed in this process, which led them to suggest that concerted two bond cleavage occurs whenever a sufficiently stable radical is formed, and that the intermediate $\mathrm{RCO}_{2}{ }^{\bullet}$ is not involved. ${ }^{4}$

In an attempt to look more closely into this problem, Falvey and Schuster noted that peroxyester photolysis "leads to chemical reactions that appear to mimic closely those of their. . . thermolyses", 5 and in a landmark experiment studied the laser flash photolysis of tert-butyl-9-methylfluorene-9percarboxylate (TBFC) at $266 \mathrm{~nm}$ excitation wavelength with $\sim 20$ ps time resolution. They reported a first order transient absorption rise with a time constant of $55 \mathrm{ps,} \mathrm{which} \mathrm{they}$ attributed to the 9-methylfluorenyl radical $\mathrm{MF}^{\bullet}$ formed in the decarboxylation of the intermediate aroyloxyl radical $\mathrm{MFCO}_{2}{ }^{\circ}$. They also pointed out that because of the very high stability of the $\mathrm{MF}^{\bullet}$ radical, according to Bartlett's proposition, the observed lifetime of the $\mathrm{MFCO}_{2}{ }^{\circ}$ radical should represent a lower limit for aroyloxyl radical lifetimes in general. As a consequence, a two step sequential mechanism as depicted in Scheme 1 would be the

\footnotetext{
${ }^{a}$ Abteilung Spektroskopie und Photochemische Kinetik, Max-PlanckInstitut für Biophysikalische Chemie, 37070 Göttingen, Germany

${ }^{b}$ Institut für Physikalische Chemie, Georg-August-Universität

Göttingen, Tammannstraße 6, 37077 Göttingen, Germany
}

rule, with decarboxylation rates becoming very rapid for highly stable product radicals being formed, but probably not exceeding $2 \times 10^{10} \mathrm{~s}^{-1}$. This conclusion by Falvey and Schuster found support in later photolysis studies showing that aroyloxyl radicals generally decarboxylate on time scales ranging from about 50 ns to a few microseconds. ${ }^{6-11}$ Also a recent study of the photolysis of organic peroxides containing coumarin or bis(phenylethynyl)benzene chromophores showed that $\mathrm{CO}_{2}$ formation occurs on a microsecond timescale indicating sequential fragmentation via intermediate carbonyloxyl radicals. ${ }^{12,13}$

However, $308 \mathrm{~nm}$ photolysis of TBFC as studied by picosecond UV-pump/IR-probe spectroscopy was shown to generate $\mathrm{CO}_{2}$ within a few picoseconds. ${ }^{14}$ Equally rapid $\mathrm{CO}_{2}$ formation was also observed in the UV-photolysis of several diaroylperoxides, tert-butyl-benzoylperoxide, and tert-butylphenylperoxycarbonate (TBPC). ${ }^{15,16}$ These results would be consistent with a concerted fragmentation mechanism via the electronically excited singlet state without formation of the $\mathrm{RCO}_{2}{ }^{\bullet}$ intermediate. On the other hand, a slower build-up of $\mathrm{CO}_{2}$ with a time constant of 30 ps was found in the photolysis of tert-butyl-2-naphthylperoxycarbonate ${ }^{15}$ (TBNC), which one might consider as being due to fast sequential bond breakage on a time scale suggested by Falvey and Schuster for TBFC.

Of course, the ability to distinguish between concerted and sequential mechanisms heavily depends on the time scale accessible to observation. Looking at peroxide decomposition with higher time resolution by femtosecond pump-probe spectroscopy in the visible to near IR spectral range ${ }^{17,18}$ led to the suggestion that, in fact, the reaction mechanism involves an ultrafast sequence of elementary steps. ${ }^{19}$ A quantitative model was developed in which instantaneous $\mathrm{O}-\mathrm{O}-$ bond scission generates vibrationally highly excited $\mathrm{RCO}_{2}{ }^{\bullet}$ that may rapidly decarboxylate while simultaneously undergoing vibrational energy relaxation (VER). The rates of simultaneous $\mathrm{CO}_{2}$ formation and $\mathrm{RCO}_{2}{ }^{\bullet}$ decay depend on vibrational excess energy, VER rates and barrier heights to $\mathrm{RCO}_{2}{ }^{\bullet}$ decarboxylation. This model successfully described the 


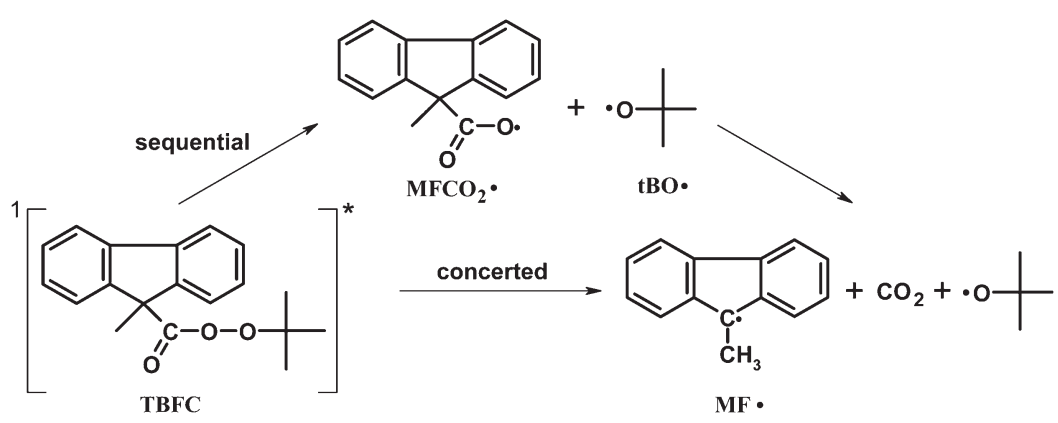

Scheme 1 Suggested reaction pathways of TBFC photodecomposition.

photodecomposition of TBFC as monitored by femtosecond time-resolved spectroscopy in the visible to near IR spectral region. ${ }^{20}$ One should note that also in these experiments TBFC decomposition was found to occur on a timescale of a few picoseconds.

The validity of interpreting this ultrafast decomposition rate in terms of a sequential mechanism, however, rests upon the correct assignment of transient spectra in the visible and near IR. Radical absorption spectra and excited state absorption are known for a very few cases only, and spectral overlap as well as time-dependent spectral shifts and band shapes complicate the analysis. As we have shown recently, such complications can be largely avoided by using broadband IR probe pulses, in particular if one focuses on the spectral region in the vicinity of the CO-group stretch band. ${ }^{21,22}$ There we studied the photodissociation mechanism of peroxycarbonates TBNC and TBPC by monitoring the temporal evolution of vibrational marker bands. In both peroxides UV excitation populates the $\mathrm{S}_{1}$ state of the parent molecule state which subsequently decays at the same rate as the final products $\mathrm{CO}_{2}, \mathrm{RO}^{\bullet}$ and $t \mathrm{BO}^{\bullet}$ appear. A sequential dissociation mechanism could be ruled out unequivocally. Also the somewhat slower fragmentation of TBNC $(25-50 \mathrm{ps})$ is a consequence of the correspondingly longer $\mathrm{S}_{1}$ lifetime. ${ }^{21}$ A similar study on dibenzoylperoxide revealed the same initial pattern of the photofragmentation mechanism. ${ }^{22}$

In the present paper we report results of applying the same technique to investigate the photodecomposition of TBFC with the goal of finally settling the issue about its photofragmentation pathway. For that purpose we also study the appropriately ${ }^{13} \mathrm{C}$-labelled compound to verify the mechanism and the assignment of transient bands. This seems of particular relevance, as this reaction is often quoted as a kind of benchmark when referring to organic peroxide decarboxylation mechanisms and rates.

\section{Experimental technique}

The femtosecond infrared experiments were carried out with a laser system based on a $1 \mathrm{kHz} \mathrm{Ti}$ : sapphire oscillator/regenerative amplifier system (wavelength $800 \mathrm{~nm}$, pulse width $100 \mathrm{fs}$, pulse energy $700 \mu \mathrm{J}$ ). Pump pulses at $267 \mathrm{~nm}$ were produced by frequency tripling part of the $800 \mathrm{~nm}$ light. The UV light was attenuated to energies of $0.5-2 \mu \mathrm{J}$ and used to excite $0.5-2 \mathrm{mM}$ solutions of TBFC dissolved in $\mathrm{CD}_{3} \mathrm{CN}$ (Deutero $\mathrm{GmbH}$, $99.6 \%$ deuteration grade), $\mathrm{CCl}_{4}$, or $n$-heptane. Tunable mid-infrared pulses were generated by difference frequency mixing of idler and signal from an optical parametric amplifier $^{23,24}$ pumped by $250 \mu \mathrm{J}$ pulse energy of the regenerative amplifier output. The IR light was split in a probe and a reference beam and focused into the sample cell. At the sample position the probe pulse was superimposed on the pump beam. To avoid signal contributions arising from rotational relaxation of molecules the relative plane of polarization of both pulses was adjusted to $54.7^{\circ}$. After passing the cell both IR beams were spectrally dispersed in a grating polychromator and independently imaged on a HgCdTe detector $(2 \times 32$ elements $)$. The whole pump-probe setup was purged with dry nitrogen to avoid spectral and temporal distortion of the IR pulses by $\mathrm{CO}_{2}$ and water absorptions in air. All experiments were performed in a stainless steel flow cell equipped with $1 \mathrm{~mm}$ thick $\mathrm{CaF}_{2}$ windows (the path length inside the cell was $0.6 \mathrm{~mm}$ ).

TBFC and carbonyl- ${ }^{13} \mathrm{C}$-labeled TBFC were prepared from a reaction of the corresponding acid chlorides with sodium tert-butyl peroxide according to ref. 25 . The synthesis of these acid chlorides started from methylation of fluorene to 9-methyl-9H-fluorene ${ }^{26}$ and subsequent carboxylation to 9methyl-9H-fluorene-9-carboxylic acid by treatment of 9-methyl-9H-fluorene with buthyllithium in $\mathrm{THF}$ at $-78{ }^{\circ} \mathrm{C}$ followed by discharging gaseous $\mathrm{CO}_{2}$ into the solution. ${ }^{27}$ For the synthesis of ${ }^{13} \mathrm{C}$-TBFC the latter reaction step was carried out with ${ }^{13} \mathrm{CO}_{2}$. The acids were transformed into acid chlorides by means of $\mathrm{PCl}_{5}$.

The measured IR spectra were compared with quantum chemical calculations of TBFC and the corresponding radicals. We applied density functional theory (DFT) using the ORCA program package ${ }^{28,29}$ developed by Neese and coworkers. To enhance the efficiency of the calculations the resolution-of-identity (RI) approximation was invoked. ${ }^{30}$ Since this procedure requires a non-hybrid functional, we have chosen the Becke-Perdew functional, BP86. ${ }^{31,32}$ The Ahlrichs' triple- $\zeta$ valence basis set, ${ }^{33}$ TZVPP, with three sets of polarization functions on all atoms was applied, to which diffuse functions from Dunning's correlation-consistent polarized triple- $\zeta$ basis set could be added (hence, aug-TZVPP). ${ }^{34}$ In addition, the RI-approximation requires an auxiliary Coulomb fitting basis $(\mathrm{TZV} / \mathrm{J})$ for the triple- $\zeta$ valence basis set, which was taken from the TURBOMOLE library. ${ }^{35}$ Following the recommendations by Neugebauer and Hess ${ }^{36}$ for calculations at the RI-DFT/TZVPP level of theory, a correction factor of 1.004 for conversion from harmonic to fundamental vibrational frequencies was used. 


\section{Results and discussion}

Fig. 1a shows linear absorption spectra of TBFC and ${ }^{13} \mathrm{C}$ $\mathrm{TBFC}$ in $\mathrm{CD}_{3} \mathrm{CN}$. The spectrum of $\mathrm{TBFC}$ is characterized by a strong carbonyl stretching band at $1766 \mathrm{~cm}^{-1}$ which upon labelling red-shifts to $1723 \mathrm{~cm}^{-1}$. Absorption bands in the fingerprint region correspond to vibrations of the fluorenyl and tert-butyl rest and are hence almost unaffected by ${ }^{13} \mathrm{C}$-labeling of the carbonyl group.

In Fig. 1b transient difference spectra recorded 1.3 ns after $\mathrm{UV}$ excitation of TBFC and ${ }^{13} \mathrm{C}-\mathrm{TBFC}$ in $\mathrm{CD}_{3} \mathrm{CN}$, respectively, are presented for the frequency range $1300-1820 \mathrm{~cm}^{-1}$. Because of the limited bandwidth of the IR probe pulse they were constructed from several overlapping spectra of $\sim 100 \mathrm{~cm}^{-1}$ width. The estimated error of the relative amplitudes of spectral features arising from this procedure is estimated to be $<20 \%$. At $2220-2400 \mathrm{~cm}^{-1}$ where the solvent $\mathrm{CD}_{3} \mathrm{CN}$ is opaque separate transient spectra of TBFC and ${ }^{13} \mathrm{C}$-TBFC in $n$-heptane are shown. This part of the spectrum is not to scale. The transient spectra show negative peaks caused by bleaching of the peroxide and positive absorptions due to the formation of photoproducts. Most prominent is the bleaching of the $\mathrm{CO}$ stretching bands but also vibrations at 1369 and $1453 \mathrm{~cm}^{-1}$ clearly show the disappearance of TBFC and ${ }^{13} \mathrm{C}$-TBFC, respectively, as indicated by full circles. The strongest increase of absorption arises from the asymmetric stretching vibration of newly formed $\mathrm{CO}_{2}$ at $2337 \mathrm{~cm}^{-1}$ and ${ }^{13} \mathrm{CO}_{2}$ at $2273 \mathrm{~cm}^{-1}$, respectively (open circle in Fig. 1b). In the

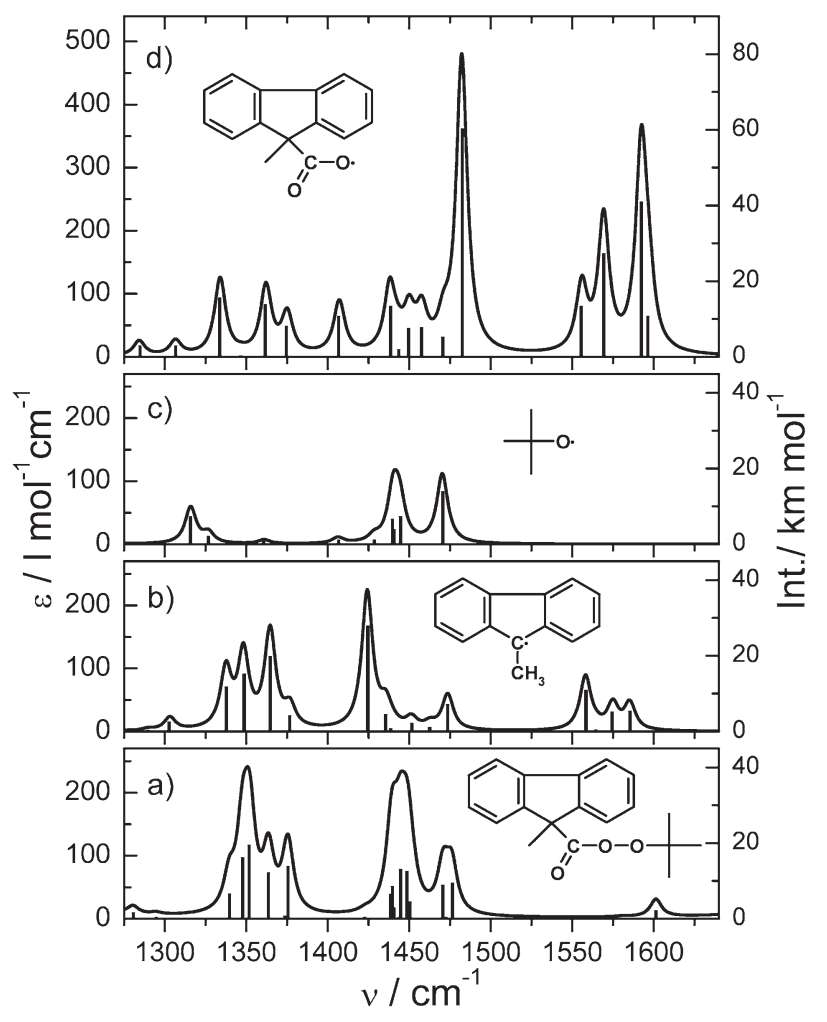

Fig. 2 Calculated IR spectra of (a) $\mathrm{TBFC}$, (b) $\mathrm{MF}^{\bullet}$, (c) $t \mathrm{BO}^{\bullet}$, and (d) $\mathrm{MFCO}_{2}{ }^{\bullet}$; computed frequencies and intensities (bars, right scale) were convoluted with a uniform Lorentzian line shape of $8 \mathrm{~cm}^{-1}$ width (FWHM).
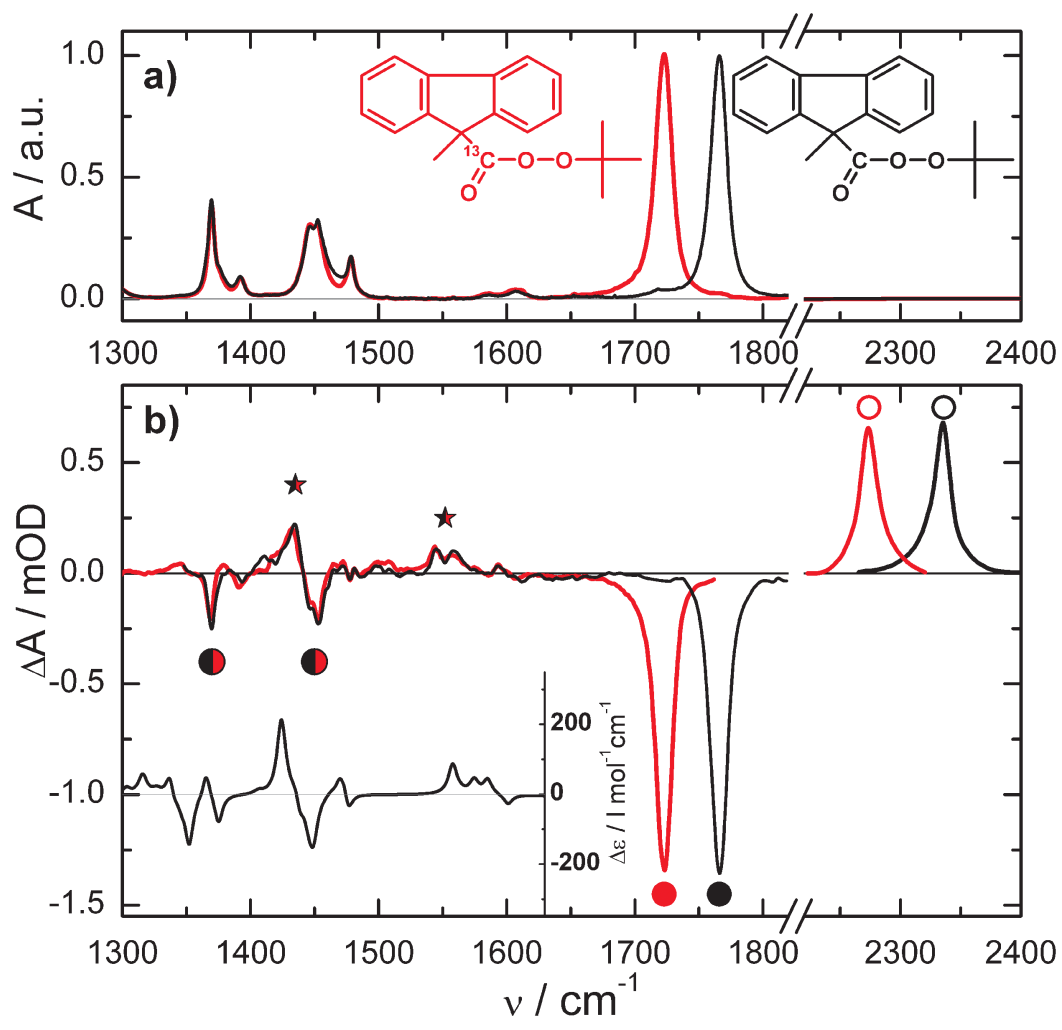

Fig. 1 (a) Linear absorption spectra of TBFC (black) and ${ }^{13} \mathrm{C}-\mathrm{TBFC}$ (red) in $\mathrm{CD}_{3} \mathrm{CN}$; (b) transient difference spectra $1.3 \mathrm{~ns}$ after $267 \mathrm{~nm}$ excitation of TBFC (black) and ${ }^{13} \mathrm{C}$-TBFC (red) in $\mathrm{CD}_{3} \mathrm{CN}$ (at $2220-2380 \mathrm{~cm}^{-1}$ spectra were recorded in $n$-heptane, because $\mathrm{CD}_{3} \mathrm{CN}$ is opaque in this range); symbols indicate bleaching of TBFC (filled circles) and formation of the products $\mathrm{CO}_{2}$ (open circles) and methylfluorenyl radical MF ${ }^{\bullet}$ (stars); the insert shows the calculated difference spectrum of $\varepsilon\left(\mathrm{MF}^{\bullet}\right)+\varepsilon\left(t \mathrm{BO}^{\bullet}\right)-\varepsilon(\mathrm{TBFC})$ (see Fig. 2). 


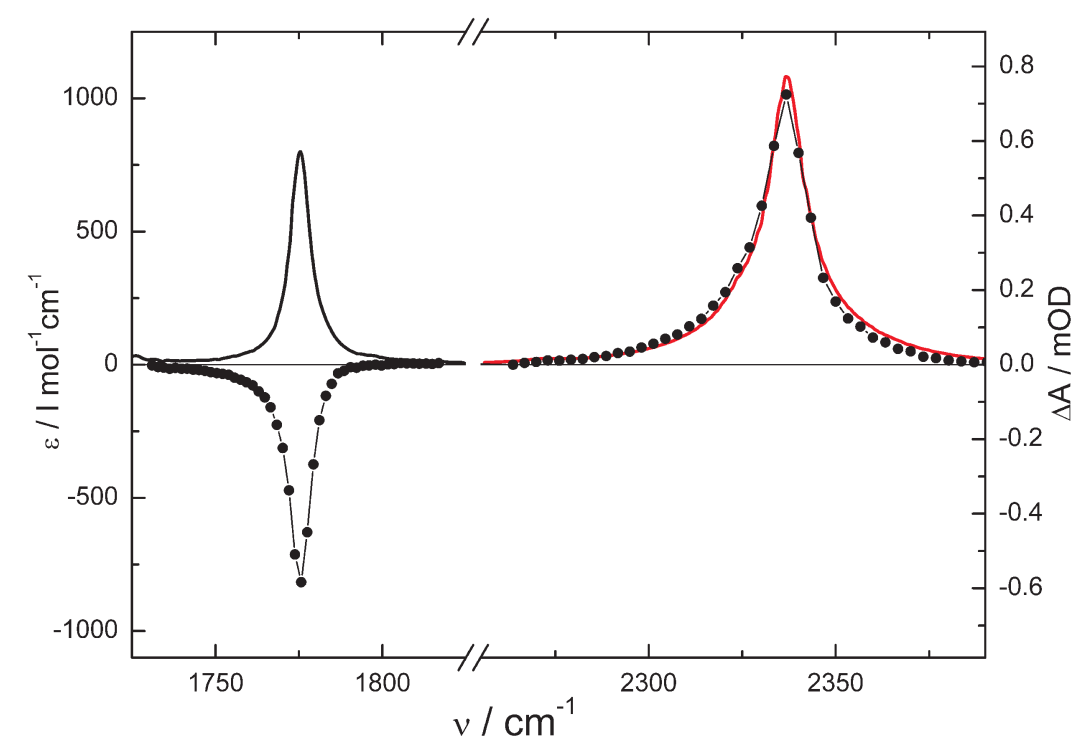

Fig. $3 \mathrm{CO}_{2}$ quantum yield of TBFC photodissociation in $n$-heptane at $1.3 \mathrm{~ns}$. Solid lines represent extinction coefficients (left scale) of TBFC COstretch (black) and of $\mathrm{CO}_{2}$ asymmetric stretch (red). The transient difference spectrum at $1.3 \mathrm{~ns}$ pump-probe delay (right scale, filled circles) is normalized to the $\mathrm{CO}$-stretch extinction coefficient. The relative amplitude of the absorption bands suggests a $\mathrm{CO}_{2}$ quantum yield of $\Phi_{\mathrm{CO}_{2}}=0.95 \pm 0.10$.

fingerprint region bands at $1434 \mathrm{~cm}^{-1}$ and, additionally, weaker absorptions at 1544 and $1559 \mathrm{~cm}^{-1}$ for both, TBFC and ${ }^{13} \mathrm{C}$-TBFC appear as marked by asterisks. As no isotope shift can be detected we attribute these bands to the $\mathrm{MF}^{\bullet}$ radical.

This assignment is supported by our DFT calculations presented in Fig. 2. Here the IR intensities (stick spectra, right ordinate) of TBFC (a) and all the radicals to be considered (b-d) are plotted. For a better comparison with the experiment smooth spectra were generated (full lines, left ordinate) assuming a uniform Lorentzian line shape of $8 \mathrm{~cm}^{-1}$ width (FWHM). The calculated spectrum of TBFC appears to be in fairly good agreement with the experimental one of Fig. 1a. Note that in the range $1280-1640 \mathrm{~cm}^{-1}$ the absorptions of TBFC, $\mathrm{MF}^{\bullet}$, and $t \mathrm{BO}{ }^{\bullet}$ are relatively weak, whereas $\mathrm{MFCO}_{2}{ }^{\bullet}$ shows two strong bands at 1483 and $1592 \mathrm{~cm}^{-1}$. These bands do not appear in the transient spectrum (Fig. 1b). Instead, the absorptions marked by asterisks in Fig. 1b agree well (both, in frequency and intensity) with the calculated spectrum of $\mathrm{MF}^{\bullet}$. Assuming that the photodecomposition of TBFC is complete after 1.3 ns the difference spectrum can be calculated from the sum of spectra of $\mathrm{MF}^{\bullet}+t \mathrm{BO}^{\bullet}-\mathrm{TBFC}$ from Fig. 2 (neglecting $\mathrm{CO}_{2}$ which does not absorb in this spectral range). The result is shown in the insert of Fig. $1 \mathrm{~b}$ and is in very good agreement with the measured difference spectrum.

The conversion efficiency of TBFC to the final products can also be determined by measuring the relative $\mathrm{CO}_{2}$ quantum yield. To this end in Fig. 3 the absorption coefficients of TBFC (at the CO-stretching band, black line) and $\mathrm{CO}_{2}\left(\nu_{3}\right.$ band, red line) in $n$-heptane are compared with the scaled transient difference spectrum (filled circles) at $1.3 \mathrm{~ns}$ pump-probe delay. Fig. 3 clearly shows that the ratio of transient TBFC bleach and $\nu_{3}$ absorption matches the ratio of the corresponding extinction coefficients, suggesting that every decomposed TBFC generates just one $\mathrm{CO}_{2}$ molecule and no significant residue of $\mathrm{MFCO}_{2}{ }^{\circ}$. These findings preclude a sequential dissociation mechanism leading to vibrationally hot $\mathrm{MFCO}_{2}{ }^{\bullet}$ radicals from which an appreciable amount cools down to thermal equilibrium and lives for many nanoseconds. ${ }^{20}$

The photofragmentation mechanism of TBFC may be deduced from the time evolution of transient spectra in the picosecond time range. The contour diagram of Fig. 4 shows that immediately upon UV excitation, $\mathrm{CO}$ stretch bands in the electronic ground and first excited state of TBFC appear as a superposition of bleach (blue, centered at $1767 \mathrm{~cm}^{-1}$ ) and a red-shifted absorption (red), respectively. With increasing pump-probe delay the excited state population decays and only the ground state bleach remains. An exponential fit to the integrated band intensity (upper panel in Fig. 4) gives a $S_{1}$ lifetime of $\tau_{\mathrm{S} 1}=(0.8 \pm 0.2)$ ps. The $\mathrm{S}_{1}$ spectrum was reconstructed by subtracting the ground state bleach (i.e. the spectrum at $8 \mathrm{ps}$ ) from the $t=0.38 \mathrm{ps}$ spectrum and then extrapolating the amplitude to $t=0$. The result is presented in the right panel of Fig. 4 and demonstrates that the CO-stretch band in the $S_{1}$ state peaks at $1760 \mathrm{~cm}^{-1}$ and is slightly broader than the bleach component at 8 ps resembling the ground state spectrum.

In $\mathrm{CCl}_{4}$ and $n$-heptane the $\mathrm{S}_{1}$ lifetime of TBFC is found to be $(1.5 \pm 0.3)$ and $(2.1 \pm 0.3) \mathrm{ps}$, respectively. Such a pronounced solvent effect on $\tau_{\mathrm{S} 1}$ was also observed for the photofragmentation of peroxycarbonates and discussed in terms of a possible polarity effect on the barrier height of the dissociation coordinate. ${ }^{21}$ As for the peroxycarbonates, however, it is not known for TBFC either whether the fragmentation is actually a barrier-controlled process. Temperature dependent measurements may help to clarify this point. On the basis of Fig. 3 we have concluded that each photo-bleached TBFC molecule generates one $\mathrm{CO}_{2}$. The short $\mathrm{S}_{1}$ lifetime of TBFC suggests that other deactivation processes repopulating the ground state (fluorescence, internal 


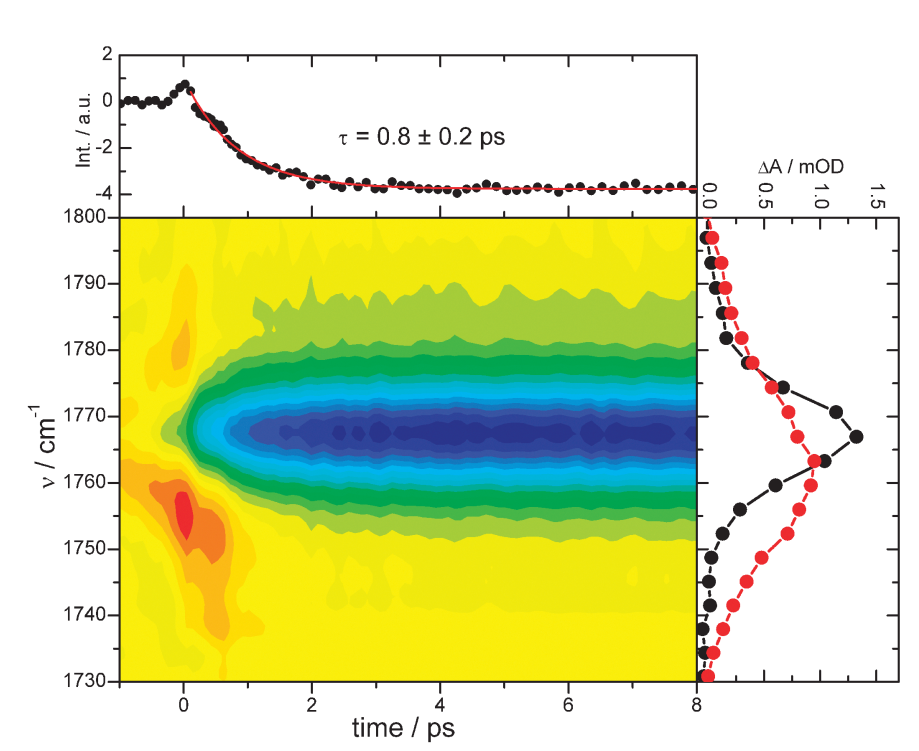

Fig. 4 Spectral evolution of the $\mathrm{CO}$ stretch absorption band of $\mathrm{TBFC}$ in $\mathrm{CD}_{3} \mathrm{CN}$. At early times the spectrum consists of a superposition of ground state bleach (blue) and red shifted $\mathrm{S}_{1}$ absorption (red). The reconstructed spectra are shown in the right panel. Upper panel: integrated band intensity (red curve: exponential fit to the data with time constant of $0.8 \pm 0.2 \mathrm{ps}$ ).).

conversion) cannot compete with fragmentation. Consequently, the quantum yield of direct $\mathrm{CO}_{2}$ formation from the $S_{1}$ state has to be close to unity.

Fig. 5 presents formation of the photoproduct $\mathrm{MF}^{\bullet}$ at a probe frequency of around $1550 \mathrm{~cm}^{-1}$ after UV excitation of TBFC in $\mathrm{CD}_{3} \mathrm{CN}$. The contour diagram shows that until a pump-probe delay of 20 ps the absorption is broad and redshifted with respect to the final spectrum which is characterized by a double peak. This behaviour is a clear signature of a hot species relaxing by vibrational energy transfer to the surrounding solvent. The rate of $\mathrm{MF}^{\bullet}$ formation is deduced from the band integral as plotted in the upper panel of Fig. 5 and
$\mathrm{t}-\mathrm{BMFP} / \mathrm{CD}_{3} \mathrm{CN}$

demonstrates a very fast production of the radical within the $\mathrm{S}_{1}$ lifetime of TBFC. Subsequently no further increase of the $\mathrm{MF}^{\bullet}$ concentration can be observed up to $1.3 \mathrm{~ns}$ after excitation.

A similar behaviour is found for the production of $\mathrm{CO}_{2}$ not shown here. Again the fragment is generated within the $\mathrm{S}_{1}$-lifetime of the parent molecule. In accordance with earlier IR studies on the decarboxylation of $\mathrm{TBFC}^{14}$ and other peroxides ${ }^{15,16,21,22}$ the $\mathrm{CO}_{2}$ molecule is generated with high vibrational excess energy. A quantitative analysis of the transient IR spectra on the basis of a model of anharmonically coupled oscillators described previously ${ }^{16,21,37}$ reveals an initial $\mathrm{CO}_{2}$ vibrational temperature of $T_{0}=(2500 \pm 200) \mathrm{K}$.

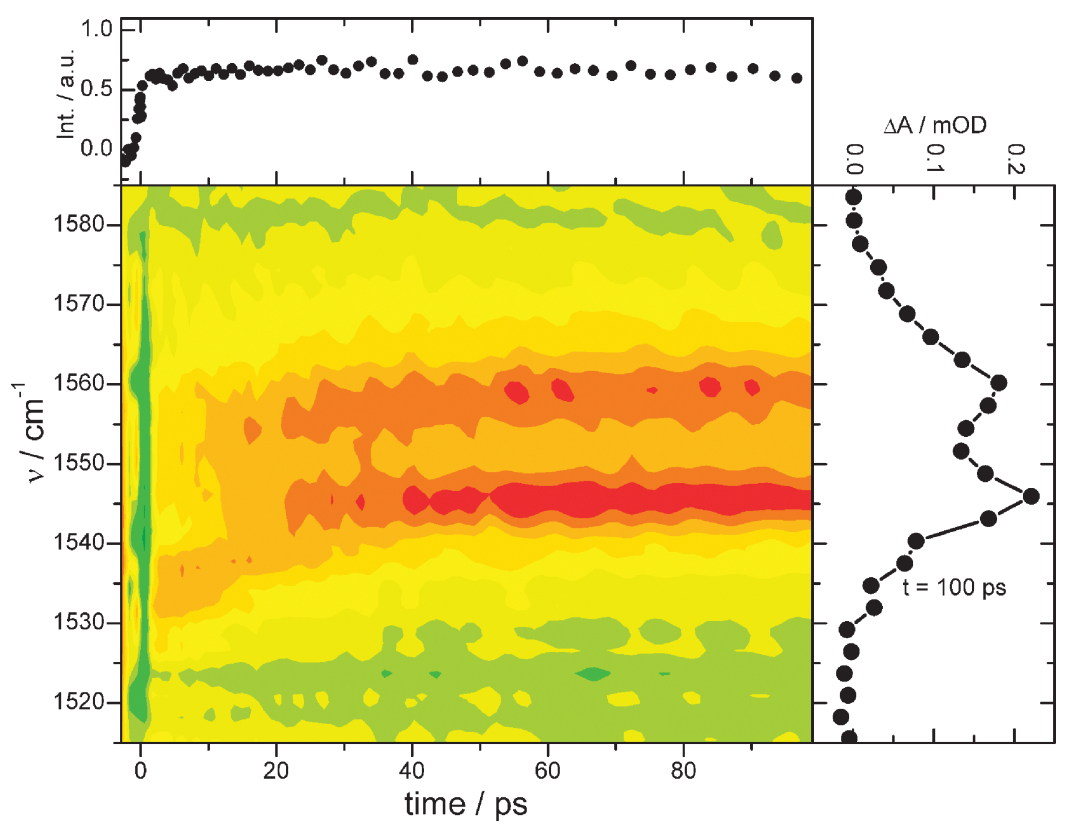

Fig. 5 Spectral evolution in the $1515-1585 \mathrm{~cm}^{-1}$ range after photodissociation of $\mathrm{TBFC}$ in $\mathrm{CD}_{3} \mathrm{CN}$; right panel: transient spectrum at $100 \mathrm{ps}$ pump-probe delay; upper panel: integrated band intensity. 


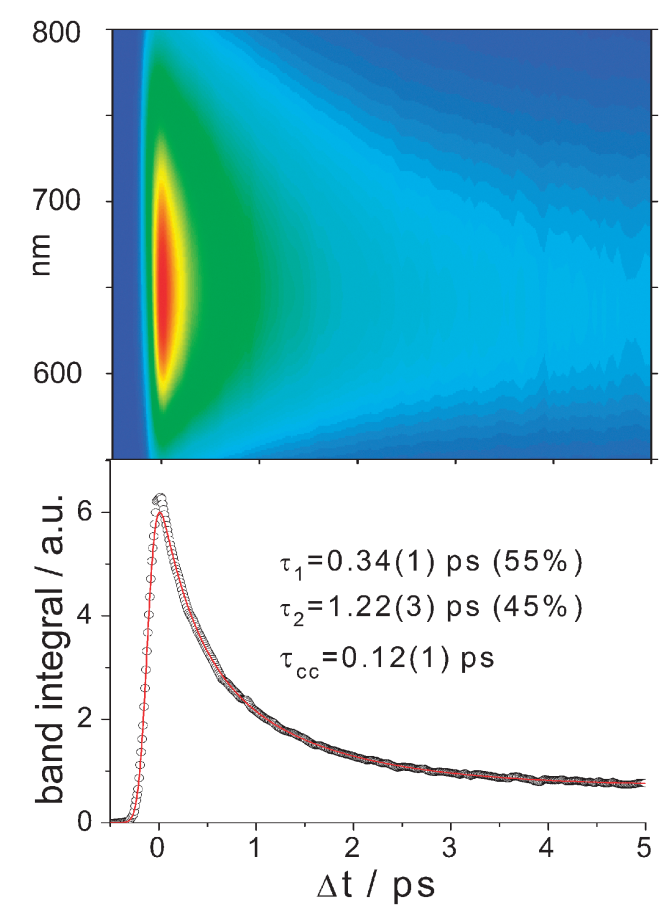

Fig. 6 Spectral evolution of the main transient absorption band in the visible after UV-excitation of TBFC in propylene carbonate solution. ${ }^{20}$ The bottom graph shows the decay of the band integral over the wavelength range shown in the contour plot. $\tau_{\mathrm{cc}}$ denotes the pump-probe cross correlation width fitted to the observed absorption rise.

\section{Summary and conclusion}

Our results for the TBFC photo-fragmentation can be summarized as follows:

(1) The $S_{1}$-lifetime of the photo-excited TBFC molecule is solvent dependent and amounts to $\tau_{\mathrm{S} 1}=(0.8 \pm 0.2),(1.5 \pm$ $0.3)$, and $(2.1 \pm 0.3)$ ps in $\mathrm{CD}_{3} \mathrm{CN}, \mathrm{CCl}_{4}$, and $n$-heptane, respectively.

(2) $\mathrm{CO}_{2}$ and the radical $\mathrm{MF}^{\bullet}$ are formed with the same rate as the electronically excited TBFC molecule decays. Both fragments are generated with excess vibrational energy. For $\mathrm{CO}_{2}$ this energy corresponds to an initial vibrational temperature of $T_{0}=(2500 \pm 200) \mathrm{K}$.

(3) The quantum yield of $\mathrm{CO}_{2}$ is $\Phi_{\mathrm{CO}_{2}}=0.95 \pm 0.10$.

In contrast to the original implication by Falvey and Schuster, a sequential bond breakage mechanism with a spectroscopically accessible intermediate $\mathrm{MFCO}_{2}{ }^{\bullet}$ fragment is clearly not operative in this reaction. Therefore, in terms of photochemical kinetics the mechanism may be considered as concerted. The question whether both bonds break synchronously cannot be answered on the basis of our experiments. The product rise time constant of about 25 ps reported by Falvey and Schuster, which at that time was at the limit of the experimental time resolution, could not be found, as already noted in previous studies. ${ }^{14,20}$ The main part of the transient visible absorption band centred around $650 \mathrm{~nm}$ decays on a time scale of about $0.75 \mathrm{ps}$ in propylene carbonate solution as illustrated in Fig. 6. Therefore, in our view the band has to be reassigned to excited state absorption from the $S_{1}$ state of TBFC. The results reported here show unequivocally that it cannot be considered as evidence for an intermediate $\mathrm{MFCO}_{2}{ }^{\bullet}$ radical.

\section{Acknowledgements}

The authors are grateful to Jens Schimpfhauser and Jürgen Bienert for the preparation and purification of TBFC and its ${ }^{13} \mathrm{C}$-labeled analogue. We also thank Jürgen Troe for continuous support of this work.

\section{References}

1 K. Fujimori, in Organic Peroxides, ed. W. Ando, Wiley, New York, 1992, p. 319.

2 Y. Sawaki, in Organic Peroxides, ed. W. Ando, Wiley, New York, 1992, p. 425.

3 G. G. Hammond and L. M. Soffer, J. Am. Chem. Soc., 1950, 72.

4 P. D. Bartlett and R. R. Hiatt, J. Am. Chem. Soc., 1958, 80, 1398-1405.

5 D. E. Falvey and G. B. Schuster, J. Am. Chem. Soc., 1986, 108, 7419-7420.

6 H. Misawa, K. Sawabe, S. Takahara, H. Sakuragi and K. Tokumaru, Chem. Lett., 1988, 357-360.

7 J. Chateauneuf, J. Lusztyk and K. U. Ingold, J. Am. Chem. Soc., 1988, 110, 2877-2885.

8 J. Chateauneuf, J. Lusztyk and K. U. Ingold, J. Am. Chem. Soc., 1988, 110, 2886-2893.

9 J. Wang, T. Tateno, H. Sakuragi and K. Tokumaru, J. Photochem. Photobiol., A, 1995, 92, 53-59.

10 J. Wang, H. Itoh, M. Tsuchiya, K. Tokumaru and H. Sakuragi, Tetrahedron, 1995, 51, 11967-11978.

11 T. Najiwara, J. Hashimoto, K. Segawa and H. Sakuragi, Bull. Chem. Soc. Jpn., 2003, 76, 575-585.

12 D. E. Polyansky, E. O. Danilov, S. V. Voskresensky, M. A. J. Rodgers and D. C. Neckers, J. Phys. Chem. A, 2006, 110, 4969-4978.

13 D. E. Polyansky and D. C. Neckers, J. Phys. Chem. A, 2005, 109, 2793-2800.

14 J. Aschenbrücker, U. Steegmüller, M. Buback, N. P. Ernsting and J. Schroeder, J. Phys. Chem. B, 1998, 102, 5552-5555.

15 J. Aschenbrücker, U. Steegmüller, M. Buback, N. P. Ernsting and J. Schroeder, Ber. Bunsen-Ges. Phys. Chem., 1998, 102, 965.

16 M. Buback, M. Kling, M. T. Seidel, F. D. Schott, J. Schroeder and U. Steegmüller, Z. Phys. Chem., 2001, 215, 717-736.

17 B. Abel, J. Assmann, P. Botschwina, M. Buback, M. Kling, R. Oswald, S. Schmatz, J. Schroeder and T. Witte, J. Phys. Chem. A, 2003, 107, 5157-5167.

18 B. Abel, J. Assmann, M. Buback, C. Grimm, S. Schmatz, J. Schroeder and T. Witte, J. Phys. Chem. A, 2003, 107, 9499-9510.

19 M. Buback, M. Kling, S. Schmatz and J. Schroeder, Phys. Chem. Chem. Phys., 2004, 6, 5441-5455.

20 B. Abel, M. Buback, M. Kling, S. Schmatz and J. Schroeder, J. Am. Chem. Soc., 2003, 125, 13274-13278.

21 C. Reichardt, J. Schroeder and D. Schwarzer, J. Phys. Chem. A, 2007, 111, 10111-10118.

22 C. Reichardt, J. Schroeder, P. Vöhringer and D. Schwarzer, Phys. Chem. Chem. Phys., 2008, 10, 1662-1668.

23 R. A. Kaindl, M. Wurm, K. Reimann, P. Hamm, A. M. Weiner and M. Woerner, J. Opt. Soc. Am. B, 2000, 17, 2086-2094.

24 P. Hamm, R. A. Kaindl and J. Stenger, Opt. Lett., 2000, 25, $1798-1800$.

25 J. P. Lorand and P. D. Bartlett, J. Am. Chem. Soc., 1966, 88, 3294-3302.

26 D. Zhang, L. Chen, J. Chen, Y. Liang and H. Zhou, Synth. Commun., 2005, 35, 2609-2613.

27 C. Garms and W. Francke, in Treatment of contaminated soils, ed. R. Stegmann, G. Brunner, W. Calmano and G. Matz, Springer, Berlin, 2001, pp. 95-131.

28 F. Neese, University of Bonn, 2007.

29 F. Neese, J. Am. Chem. Soc., 2006, 128, 10213.

30 F. Neese, J. Comput. Chem., 2003, 24, 1740.

31 A. D. Becke, Phys. Rev. A: At., Mol., Opt. Phys., 1988, 38, 3098. 
32 J. P. Perdew, Phys. Rev. B: Condens. Matter Mater. Phys., 1986, 33, 8822 .

33 A. Schaefer, H. Horn and R. Ahlrichs, J. Chem. Phys., 1992, 97, 2571.

34 R. A. Kendall, T. H. Dunning, Jr and R. J. Harrison, J. Chem. Phys., 1992, 96, 6769.
35 K. Eichkorn, O. Treutler, H. Ohm, M. Haser and R. Ahlrichs, Chem. Phys. Lett., 1995, 240, 283.

36 J. Neugebauer and B. A. Hess, J. Chem. Phys., 2003, 118 7215.

37 P. Hamm, S. M. Ohline and W. Zinth, J. Chem. Phys., 1997, 106, 519-529. 